\title{
Neoadjuvant Chemoradiotherapy for Stage II or III Esophageal Squamous Cell Carcinoma
}

\author{
TAKAHARU KAWAI, MITSUGU KOCHI, MASASHI FUJII, KEIO SONG, KEN HAGIWARA, \\ MEGUMU WATANABE, YORITAKA MATSUNO, HIROSHI SUDA, RENPEI YAGI and TADATOSHI TAKAYAMA \\ Department of Digestive Surgery, Nihon University School of Medicine, Tokyo, Japan
}

\begin{abstract}
Background/Aim: The goal of this retrospective study was to investigate the efficacy and safety of neoadjuvant chemoradiotherapy (CRT) in patients with Stage II or Stage III esophageal squamous cell carcinoma (SCC). Patients and Methods: Between January 2004 and December 2014, a total of 86 patients underwent surgical resection in conjunction with preoperative CRT for esophageal SCC in our Institute. Results: A pathological complete response was achieved in $38.7 \%$ of patients with Stage II cancer and $20 \%$ of patients with Stage III. Postoperative complications were observed in $61.3 \%$ of Stage II and $76.4 \%$ of Stage III patients. The 5-year overall survival rate (OS) was $83.2 \%$ in Stage II and $22.8 \%$ in Stage III ( $p=0.0001)$. The 5-year disease-free survival (DFS) rate was $67.9 \%$ in Stage II and $29.9 \%$ in Stage III ( $p=0.0007)$. Conclusion: Neoadjuvant CRT may improve OS and DFS rates in patients with Stage II esophageal SCC.
\end{abstract}

At $25 \%$, the rate of microscopically-positive resection margins is high in patients undergoing primary surgery for esophageal carcinoma, and the 5-year survival rate rarely exceeds $40 \%$. The results of one meta-analysis suggest that neoadjuvant chemoradiotherapy (CRT) confers a survival benefit in such patients, although often at the cost of an increase in postoperative morbidity and mortality (1). Moreover, one recent randomized control study found that preoperative CRT was safe and led to a significant increase in overall survival (OS) in patients with adenocarcinoma or squamous-cell carcinoma (SCC) of the esophagus or esophagogastric

Correspondence to: Associate Professor Mitsugu Kochi, Department of Digestive Surgery, Nihon University School of Medicine, 30-1 Ohyaguchi Kamimachi, Itabashi-ku, Tokyo 1738610, Japan. Tel: +81 339728111, Fax: +81 339578299, e-mail: kochi.mitsugu@nihon-u.ac.jp

Key Words: Esophageal cancer, chemoradiotherapy, stage II or III patients, prognosis. junction (2). That study also noted a higher rate of complete pathological response in patients with SCC compared to patients with adenocarcinoma. Even so, histological tumor type was not revealed as a prognostic factor for survival. This may have been due to the large imbalance in the number of patients in each group (SCC, 41 cases; adenocarcinoma, 134 cases) and differences in terms of clinical staging, however.

The purpose of this retrospective study was to investigate the efficacy and safety of neoadjuvant CRT in patients with Stage II or Stage III esophageal SCC.

\section{Patients and Methods}

Patient enrollment. Between January 2004 and December 2014, 86 patients with esophageal cancer were treated at the Department of Digestive Surgery in the Itabashi Hospital at Nihon University School of Medicine. All the tumors were diagnosed as SCCs based on histopathological examination of biopsy specimens. The eligibility criteria for enrollment in the present study were as follows: clinical Stage II or III tumor and no clinical evidence of metastatic spread according to the UICC International Union Agent Cancer 2002 TNM Classification of Malignant Tumors (6th Edition); a World Health Organization (WHO) performance status score of 1 or lower; adequate hematologic, renal, hepatic, and pulmonary function; no history of any other cancer or prior radioor chemotherapy. All the patients were aged between 43 and 81 years. The medical history of each patient was obtained along with the results of a physical examination, abdominal X-ray, and abdominal computed tomography (CT). Results were also obtained on tumor distribution, main and concomitant surgery, TNM stage, and histopathology. The rate of hospital deaths, defined as death during the period of hospitalization due to the surgical procedures used or any other cause within 30 days postoperatively, and surgeryrelated complications were calculated by dividing the number of patients in whom an event occurred by the total number of enrolled patients.

Radiotherapy. Radiotherapy was performed using a conventional fractionation schedule, with a total radiation dose of 40.0 Gy administered in 20 fractions of $2.0 \mathrm{~Gy} /$ day, 5 times per week. The Planned target volume (PTV) encompassed the Gross tumor volume (GTV). The superior and inferior margins of the PTV were the GTV plus $4 \mathrm{~cm}$. The lateral, anterior, and posterior margins of the PTV 
were the GTV plus $2 \mathrm{~cm}$. The GTV was defined based on the findings of an endoscopic examination.

Chemotherapy. The chemotherapy regimen consisted of 5fluorouracil (5-FU) and cis-diamminedichloroplatinum (cisplatin). The 5-FU was administered as a continuous infusion of $600 \mathrm{mg} / \mathrm{m}^{2}$ over $24 \mathrm{hr}$ on days 1-4 and 35-38. Cisplatin was administered intravenously at $60 \mathrm{mg} / \mathrm{m}^{2}$ over $2 \mathrm{hr}$ on days 1 and 35 .

Surgery. Surgery, comprising a total thoracic esophagectomy and regional lymphadenectomy for curative resection, was performed as soon as possible after completion of CRT, and preferably within 4 to 6 weeks. Until 2009, an esophagectomy plus two-field regional lymphadenectomy was the standard procedure in such cases. After 2010, however, esophagectomy plus three-field regional lymphadenectomy was considered more appropriate in cases deemed to be advanced. For all other tumors, the approach depended on the characteristics of each patient and local preferences. Gastric-tube reconstruction with cervical anastomosis was the preferred technique for restoring the continuity of the digestive tract.

Statistical analysis. Correlations between the OS curves in the two groups (Stage II and Stage III) were determined by the KaplanMeier method. Prognostic factors were analyzed by univariate analysis and logistic regression. The statistical significance of differences in survival curves was assessed with a two-sided log rank test. A $p$-value of less than 0.05 was considered to indicate statistical significance. The SAS software package for Windows, version 8.02 (SAS Institute Inc., USA) and Microsoft Excel 2003 (Microsoft Co., Ltd., Japan) were used for the statistical analysis and data calculation. Data entered into a prospectively managed database at the time of treatment were retrospectively reviewed. All data used for this study were from the last follow-up visit or contact with each patient.

\section{Results}

Stage II and Stage III. The patient characteristics and clinical and pathological stages are shown in Table I. Among the total number of patients, $31(36.0 \%)$ had Stage II and 55 $(64.0 \%)$ Stage III esophageal SCC; all underwent esophagectomy and CRT with curative intent. The median age was 64 and 63 years; men accounted for $74.2 \%$ and $81.8 \%$ of patients; and median tumor length was $30 \mathrm{~mm}$ and $50 \mathrm{~mm}$, in the Stage II and Stage III groups, respectively. Most of the tumors were located in the middle esophagus (44 of a total of 86 patients, 51.2\%). In the Stage II group, 16 of 31 patients $(51.6 \%)$ had positive lymph nodes as determined by CT compared to 47 of $55(72.7 \%)$ in the Stage III group.

Delivery and toxic effects of chemoradiotherapy. A total of 78 patients $(90.7 \%)$ received the full regimen of CRT. The most common reason for not completing the therapy was digestive symptoms. The most common Grade 3 hematologic toxic effects were leukopenia (30 of 86 patients, $34.9 \%$ ) and neutropenia ( 2 of 86 patients, $2.3 \%$ ), while the most common Grade 3 non-hematological toxic effect was anorexia (8 of
Table I. Demographics and tumor characteristics in eligible patients.

\begin{tabular}{|c|c|c|c|}
\hline Characteristics & $\begin{array}{c}\text { Stage II } \\
\mathrm{n}=31(36.0 \%)\end{array}$ & $\begin{array}{c}\text { Stage III } \\
\mathrm{n}=55(64.0 \%)\end{array}$ & p-Value \\
\hline Gender & & & 0.45 \\
\hline Man & $23(74.2)$ & $45(81.8)$ & \\
\hline Woman & $8(25.8)$ & $10(18.2)$ & \\
\hline Age (Year) & & & 0.75 \\
\hline Median [Range] & $64[50-79]$ & $63[43-81]$ & \\
\hline Location & & & 0.55 \\
\hline Upper & $3(9.7)$ & $3(5.5)$ & \\
\hline Middle & $16(51.6)$ & $28(50.9)$ & \\
\hline Lower & $12(38.7)$ & $24(43.6)$ & \\
\hline Macroscopic type & & & 0.09 \\
\hline Type1 & $5(16.2)$ & $1(1.8)$ & \\
\hline Type 2 & $25(80.6)$ & $52(94.6)$ & \\
\hline Type3 & $1(3.2)$ & $2(36.5)$ & \\
\hline Maximal diameter (mm) & & & 0.0001 \\
\hline Median [Range] & $30[20-60]$ & $50[30-140]$ & \\
\hline Clinical T Stage & & & 0.0001 \\
\hline $\mathrm{cT} 1$ & $6(19.3)$ & $3(5.5)$ & \\
\hline $\mathrm{cT} 2$ & $17(54.9)$ & $7(12.7)$ & \\
\hline cT3 & $8(25.8)$ & $43(78.2)$ & \\
\hline $\mathrm{cT} 4$ & $0(0.0)$ & $2(3.6)$ & \\
\hline Clinical N Stage & & & 0.0001 \\
\hline No & $15(48.4)$ & $3(5.5)$ & \\
\hline N1 & $12(38.7)$ & $23(41.8)$ & \\
\hline $\mathrm{N} 2$ & $4(12.9)$ & $24(43.6)$ & \\
\hline N3 & $0(0.0)$ & $5(9.1)$ & \\
\hline WHO performance status score & & 0.55 & \\
\hline 0 & $29(93.5)$ & $53(96.4)$ & \\
\hline 1 & $2(6.5)$ & $2(3.6)$ & \\
\hline CEA & & & 0.15 \\
\hline Positive & $3(9.7)$ & $12(21.8)$ & \\
\hline Negative & $28(90.3)$ & $43(78.2)$ & \\
\hline SCC & & & 0.79 \\
\hline Positive & $8(25.8)$ & 17 (30.9) & \\
\hline Negative & $23(74.2)$ & $38(69.1)$ & \\
\hline
\end{tabular}

86 patients, 9.3\%). Other effects were observed in less than $10 \%$ of patients. Table II summarizes all serious adverse events occurring during treatment.

Surgery. The median time between end of CRT and surgery was 38 days. Four patients with Stage II and four with Stage III cancers underwent a total gastrectomy for lower esophageal cancer. Complete resection, with no tumor within $1 \mathrm{~mm}$ of the resection margin, was achieved in $100 \%$ of patients in Stage II and $94.5 \%$ in Stage III (Table III). Postoperative complications are summarized in Table IV. No significant difference was observed in complications between the two groups. One patient (1.2\%) deceased in hospital; no patient deceased within 30 days postoperatively.

Pathological assessment. A pathological complete response was seen in resected specimens obtained from 12 patients 
Table II. Adverse events of chemotherapy.

\begin{tabular}{|c|c|c|c|c|c|c|}
\hline \multirow[b]{2}{*}{ Event } & \multicolumn{2}{|c|}{ Stage II $n=31$} & \multicolumn{2}{|c|}{ Stage III $n=55$} & \multicolumn{2}{|c|}{ All patients $n=86$} \\
\hline & All grades & Grade 3 & All grades & Grade 3 & All grades & Grade 3 \\
\hline Leukopenia & $22(71.0)$ & $12(38.7)$ & $40(72.7)$ & $18(32.7)$ & $62(72.1)$ & $30(34.9)$ \\
\hline Neutropenia & $12(38.7)$ & $1(3.2)$ & $23(41.8)$ & $1(1.8)$ & $35(40.7)$ & $2(2.3)$ \\
\hline Anemia & 13 (41.9) & $0(0.0)$ & $26(47.3)$ & $0(0.0)$ & $39(45.3)$ & $0(0.0)$ \\
\hline Nausea/Vomit & $25(80.6)$ & $4(12.9)$ & $45(81.8)$ & $4(7.3)$ & $70(81.4)$ & $8(9.3)$ \\
\hline Diarrhea & $3(9.7)$ & $0(0.0)$ & $4(7.3)$ & $0(0.0)$ & $7(8.1)$ & $0(0.0)$ \\
\hline Renal dysfunction & $1(3.2)$ & $0(0.0)$ & $1(1.8)$ & $0(0.0)$ & $2(2.3)$ & $0(0.0)$ \\
\hline Liver dysfunction & $0(0.0)$ & $0(0.0)$ & $3(5.5)$ & $0(0.0)$ & $3(3.5)$ & $0(0.0)$ \\
\hline General fatigue & $5(16.1)$ & $0(0.0)$ & $9(16.4)$ & $0(0.0)$ & $14(16.3)$ & $0(0.0)$ \\
\hline
\end{tabular}

Table III. Details of patients who underwent surgery.

\begin{tabular}{|c|c|c|c|}
\hline & $\begin{array}{c}\text { Stage II } \\
\mathrm{n}=31(\%)\end{array}$ & $\begin{array}{l}\text { Stage III } \\
\mathrm{n}=55(\%)\end{array}$ & $p$-Value \\
\hline Operation & & & 0.37 \\
\hline RPEG & $27(87.1)$ & $51(92.7)$ & \\
\hline Total Gastrectomy & $4(12.9)$ & $4(7.3)$ & \\
\hline Reconstruction & & & 0.24 \\
\hline Roux-en-Y & $4(12.9)$ & $4(7.3)$ & \\
\hline Gastric & $26(83.9)$ & $50(90.9)$ & \\
\hline Colon & $1(3.2)$ & $1(1.8)$ & \\
\hline \multicolumn{4}{|l|}{ Residual tumor } \\
\hline R0 & $31(100.0)$ & $52(94.5)$ & \\
\hline $\mathrm{R} 1$ & $0(0.0)$ & $3(5.5)$ & \\
\hline Bleeding (ml) & & & 0.001 \\
\hline Median [Range] & 377 [136-2384] & 337 [90-1480] & \\
\hline Operation Time (min) & & & 0.001 \\
\hline Median [Range] & 530 [327-907] & 517 [310-835] & \\
\hline Hospital Stay (day) & & & 0.23 \\
\hline Median [Range] & $41[16-208]$ & $46[15-282]$ & \\
\hline
\end{tabular}

(38.7\%) in Stage II and 11 patients $(20.0 \%)$ in Stage III. A median of 17 lymph nodes were resected in patients in the Stage-II group, and 23 in the Stage-III group. One or more positive lymph nodes in the resected specimen were found in 5 patients (16.2\%) in Stage II and 20 patients (38.2\%) in Stage III. The pathological findings are summarized in Table V.

Survival. The median follow-up was 25.6 months (range=1 .6116 months). Among 86 patients undergoing resection and dying after discharge, 34 (39.5\%) died from recurrent cancer and $2(2.3 \%)$ from other causes. The 5-year OS rate was $83.2 \%$ in Stage II and $22.8 \%$ in Stage III $(p=0.0001)$ (Figure $1)$. The 5-year Disease-free survival (DFS) rate was $67.9 \%$ in Stage II and $29.9 \%$ in Stage III ( $p=0.0007)$ (Figure 2). Both OS and DFS were significantly better in Stage II.
Table IV. Surgical complication.

\begin{tabular}{lccc}
\hline Event & $\begin{array}{c}\text { Stage II } \\
\mathrm{n}=31(\%)\end{array}$ & $\begin{array}{c}\text { Stage III } \\
\mathrm{n}=55(\%)\end{array}$ & $p$-Value \\
\hline $\begin{array}{l}\text { Complication } \\
\quad(+)\end{array}$ & & & 0.61 \\
$\quad(-)$ & $19(61.3)$ & $42(76.4)$ & \\
Leakage & $7(38.7)$ & $13(23.6)$ & \\
Recurrent nerve paralysis & $1(3.6)$ & $13(23.6)$ & \\
Abscess & $0(0.0)$ & $2(3.6)$ & \\
Pneumonia & $2(6.5)$ & $8(5.5)$ & \\
ARDS & $0(0.0)$ & $1(1.8)$ & \\
Ileus & $0(0.0)$ & $1(1.8)$ & \\
Wound infection & $4(12.9)$ & $9(16.4)$ & \\
Stenosis of anastomosis & $4(12.9)$ & $8(14.5)$ & \\
Other & $8(25.8)$ & $14(25.5)$ & \\
reoperation & $1(3.2)$ & $2(3.6)$ & \\
hospital death & $0(0.0)$ & $1(1.8)$ & \\
\hline
\end{tabular}

Table V. Pathological features.

\begin{tabular}{lccc}
\hline & $\begin{array}{c}\text { Stage II } \\
\mathrm{n}=31(36.0 \%)\end{array}$ & $\begin{array}{c}\text { Stage III } \\
\mathrm{n}=55(64.0 \%)\end{array}$ & $p$-Value \\
\hline Pathological Staging & & & 0.13 \\
$\quad$ Stage 0 & $12(38.7)$ & $11(20.0)$ & \\
Stage I & $6(19.3)$ & $2(3.8)$ & \\
Stage II & $8(25.8)$ & $20(38.2)$ & \\
Stage III & $5(16.2)$ & $20(38.2)$ & \\
Stage IV & $0(0.0)$ & $2(3.8)$ & \\
Histogical type & & & 0.66 \\
(primary region) & & $40(72.7)$ & \\
Differentiation & $18(58.1)$ & $1(1.8)$ & \\
Not differentiation & $1(3.2)$ & $14(25.5)$ & 0.12 \\
$\quad$ No cancer & $12(38.7)$ & & \\
Node dissection & & & \\
$\quad$ Median [Range] & $17[2-75]$ & $23[2-101]$ & 0.02 \\
Metastatic node & & & \\
Positive & $5(16.2)$ & $20(38.2)$ & \\
Median [Range] & $0[0-2]$ & $0[0-8]$ & \\
\hline
\end{tabular}




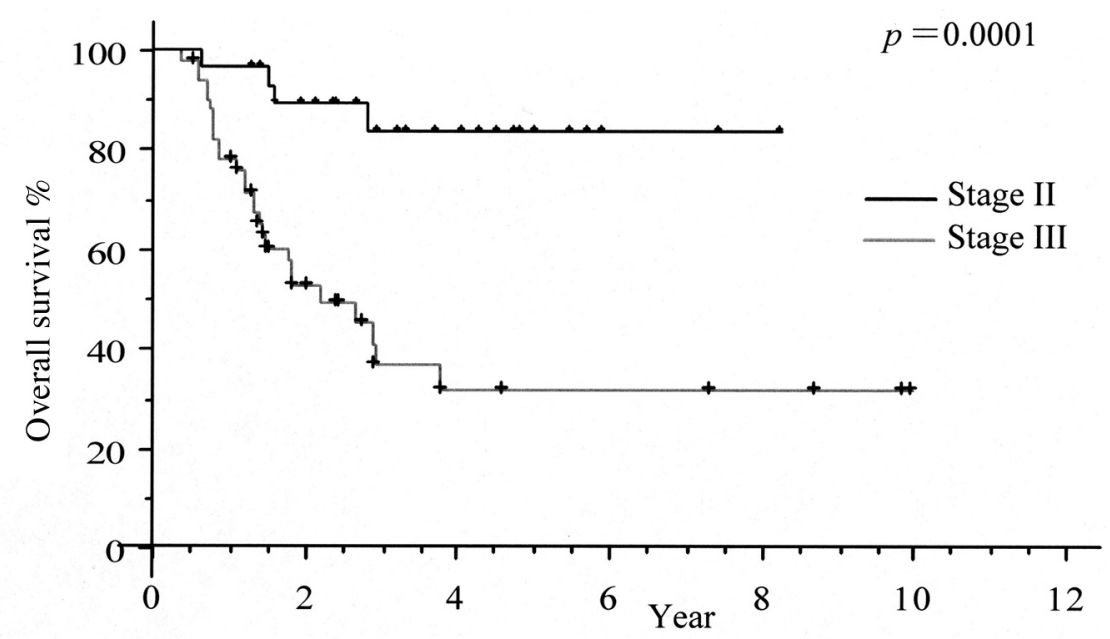

No. at Risk

$\begin{array}{llllllllllll}\text { Stage II } & 31 & 27 & 20 & 14 & 10 & 5 & 2 & 2 & 1 & 0 & 0\end{array}$

$\begin{array}{llllllllllll}\text { Stage III } & 55 & 37 & 15 & 7 & 5 & 4 & 4 & 4 & 3 & 2 & 0\end{array}$

Figure 1. Kaplan-Meier estimates of overall survival (OS) in all 86 patients. The 5-year OS rate was $83.2 \%$ in Stage II and $22.8 \%$ in Stage III $(p=0.0001)$.

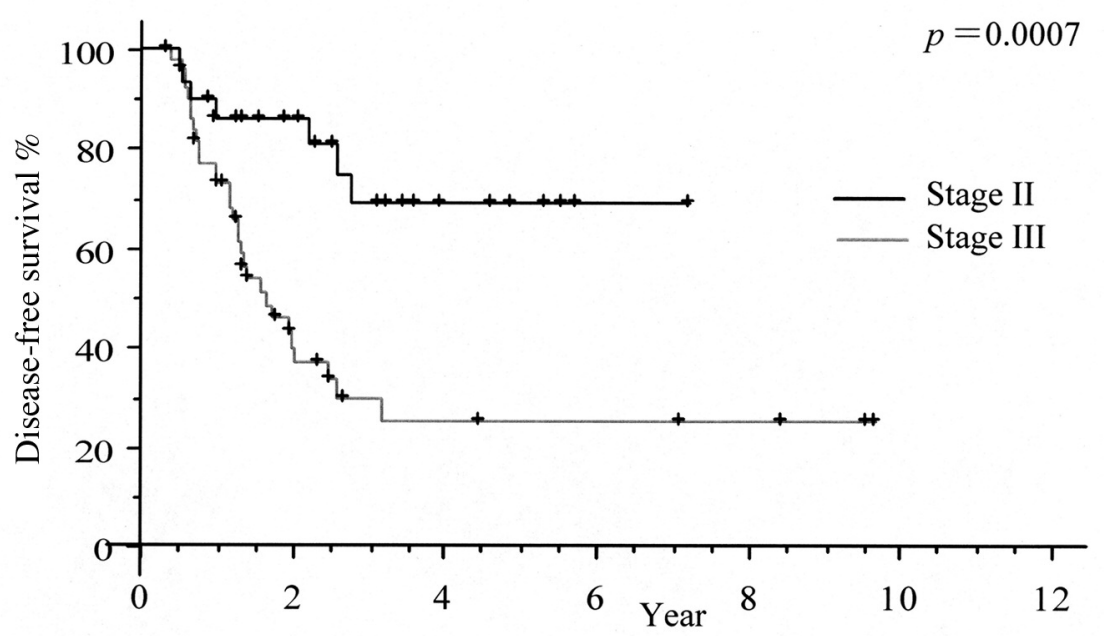

No. at Risk

$\begin{array}{lrrrrrrrrrrr}\text { Stage II } & 31 & 22 & 17 & 11 & 6 & 4 & 4 & 4 & 1 & 0 & 0 \\ \text { Stage III } & 55 & 32 & 12 & 6 & 5 & 4 & 4 & 4 & 3 & 2 & 0\end{array}$

Figure 2. Kaplan-Meier estimates of disease-free survival (DFS) in all 86 patients. The 5-year DFS rate was 67.9\% in Stage II and $29.9 \%$ in Stage III $(p=0.0007)$.

Clinical stage was identified as an independent prognostic factor in all patients (Tables VI and VII).

\section{Discussion}

The results of the present retrospective study on neoadjuvant CRT in patients with esophageal SCC revealed that OS and
DFS were significantly better in patients with Stage II disease than in those with Stage III. Chemoradiotherapy was associated with a low frequency of high-grade toxic effects, and preoperative treatment induced no increase in postoperative morbidity or early mortality. The observed difference in OS was thus clearly attributable to improved survival in the Stage II group rather than poor survival in the Stage III group. 
The role of neoadjuvant CRT has been debated for several decades, with most randomized trials finding that it conferred no survival benefit, although these studies have often been criticized for inadequate design, the small sample sizes, and poor outcomes. On the other hand, meta-analyses have suggested that neoadjuvant CRT confers a survival benefit, although often at the cost of an increase in postoperative morbidity and mortality (3-10).

One recent randomized control study of esophageal or esophagogastric-junction cancer found that preoperative CRT improved survival in patients with potentially curable disease and showed that histological tumor type was not a prognostic factor for survival in those with SCC compared with those with adenocarcinoma (2).

Previous studies of neoadjuvant CRT for esophageal cancer have included cancer of the esophagogastric-junction. Except for these cancers, the MAGIC (11) and ACCORD trials (12) also included gastric tumors in their investigation of whether such tumors should be treated with pre- or perioperative CRT. However, given that SCC is highly sensitive to radio- and chemotherapy, and that esophageal SCC and adenocarcinoma of the esophagus or esophagogastric-junction are histopathologically different, we believe that they should be considered separately.

Some studies have indicated that curative CRT is safe and may improve overall and progression-free survival rates in elderly or Stage I patients with esophageal SCC (13-15).

One recent randomized control study of cancer of the esophagus or esophagogastric-junction found that preoperative CRT yielded a higher pathological rate of complete response in patients with SCC than in those with adenocarcinoma (2). Squamous-cell carcinoma is generally highly radiosensitive, suggesting that this would be a good option in SCC of the esophagus.

In particular, the present results suggest that neoadjuvant CRT would improve the prognosis of Stage II esophageal SCC. Some studies on other types of cancer have reported that neoadjuvant chemotherapy confers a greater survival benefit in Stage II than in Stage III disease (16-17). Moreover, two large clinical trials on gastric cancer reported that postoperative chemotherapy improved the prognosis primarily in Stage II than in Stage III disease (18-20). However, research on the efficacy of adjuvant chemotherapy for Stage III gastric cancer is still ongoing (21). The present results suggest that more work is also needed to improve neoadjuvant chemotherapy for Stage III SCC esophageal cancer.

\section{Conclusion}

In conclusion, the present results indicate that neoadjuvant CRT (two courses of cisplatin and 5-FU with $40.0 \mathrm{~Gy}$ of concurrent radiotherapy) is safe and may improve OS and DFS rates in patients with Stage II esophageal SCC.
Table VI. Univariate analysis of prognostic factor for overall survival.

\begin{tabular}{|c|c|c|c|}
\hline Clinical features & $p$-Value & HR & $95 \% \mathrm{CI}$ \\
\hline Clinical Stage & 0.0008 & & \\
\hline Stage II & & 1 & \\
\hline Stage III & & 6.155 & $2.139-17.717$ \\
\hline Gender & 0.636 & & \\
\hline Female & & 1 & \\
\hline Male & & 1.241 & $0.506-3.043$ \\
\hline Location & 0.321 & & \\
\hline Upper+Middle & & 1 & \\
\hline Lower & & 2.067 & $0.493-8.671$ \\
\hline Age & 0.795 & & \\
\hline$\leq 63$ & & 1 & \\
\hline$>63$ & & 1.099 & $0.538-2.247$ \\
\hline Operation method & 0.987 & & \\
\hline Total & & 1 & \\
\hline RPEG & & 1.009 & $0.353-2.886$ \\
\hline Histrogical diagnosis & 0.017 & & \\
\hline Cancer (-) & & 1 & \\
\hline Cancer (+) & & 4.298 & $1.305-14.155$ \\
\hline CEA & 0.966 & & \\
\hline Negative & & 1 & \\
\hline Positive & & 1.021 & $0.392-2.663$ \\
\hline $\mathrm{SCC}$ & 0.475 & & \\
\hline Negative & & 1 & \\
\hline Positive & & 1.332 & $0.607-2.921$ \\
\hline Complication & 0.2443 & & \\
\hline$(-)$ & & 1 & \\
\hline$(+)$ & & 1.777 & $0.675-4.680$ \\
\hline
\end{tabular}

CI: Confidence interval.

Table VII. Multivariate analysis of prognostic factor for overall survival.

\begin{tabular}{lccc}
\hline Clinical features & $p$-Value & HR & $95 \% \mathrm{CI}$ \\
\hline Clinical Stage & 0.0006 & & \\
$\quad$ Stage II & & 1 & \\
$\quad$ Stage III & & 9.723 & $3.118-15.662$ \\
Histrogical diagnosis & & 1 & \\
$\quad$ Cancer (-) & & 3.431 & $1.037-11.346$ \\
Cancer (+) & & \\
\hline
\end{tabular}

CI: Confidence interval.

\section{Conflicts of Interest}

None of the authors have any conflicts of interest to declare.

\section{Acknowledgements}

The Authors would like to thank Professor Jeremy Williams of the Department of International Medical Communications of Tokyo Medical University for his review of this manuscript. 


\section{References}

1 Kelsen DP, Ginsberg R, Pajak TF, Sheahan DG, Gunderson L, Mortimer J, Estes N, Haller DG, Ajani J, Kocha W, Minsky BD and Roth JA: Chemotherapy followed by surgery compared with surgery alone for localized esophageal cance. N Engl J Med 339(27): 1979-1984, 1998

2 van Hagen P, Hulshof MC, van Lanschot JJ, Steyerberg EW, van Berge Henegouwen MI, Wijnhoven BP, Richel DJ, Nieuwenhuijzen GA, Hospers GA, Bonenkamp JJ, Cuesta MA, Blaisse RJ, Busch OR, ten Kate FJ, Creemers GJ, Punt CJ, Plukker JT, Verheul HM, Spillenaar Bilgen EJ, van Dekken H, van der Sangen MJ, Rozema T, Biermann K, Beukema JC, Piet AH, van Rij CM, Reinders JG, Tilanus HW and van der Gaast A: CROSS Group. Preoperative chemoradiotherapy for esophageal or junctional cancer. N Engl J Med 366(22): 20742084, 2012.

3 Malthaner R and Fenlon D: Preoperative chemotherapy for resectable thoracic esophageal cancer. Cochrane Database Syst Rev (1): CD001556, 2001.

4 Urba SG, Orringer MB, Turrisi A, Iannettoni M, Forastiere A and Strawderman M: Randomized trial of preoperative chemoradiation versus surgery alone in patients with locoregional esophageal carcinoma. J Clin Oncol 19(2): 305-313, 2001.

5 Herskovic A, Martz K, al-Sarraf M, Leichman L, Brindle J, Vaitkevicius V, Cooper J, Byhardt R, Davis L and Emami B: Combined chemotherapy and radiotherapy compared with radiotherapy alone in patients with cancer of the esophagus.N Engl J Med 326(24): 1593-1598, 1992.

6 Cooper JS, Guo MD, Herskovic A, Macdonald JS, Martenson JA Jr, Al-Sarraf M, Byhardt R, Russell AH, Beitler JJ, Spencer S, Asbell SO, Graham MV and Leichman LL: Chemoradiotherapy of locally advanced esophageal cancer: long-term follow-up of a prospective randomized trial (RTOG 85-01). Radiation Therapy Oncology Group. JAMA 281(17): 1623-1627, 1999.

7 Tepper J, Krasna MJ, Niedzwiecki D, Hollis D, Reed CE, Goldberg R, Kiel K, Willett C, Sugarbaker D and Mayer R: Phase III trial of trimodality therapy with cisplatin, fluorouracil, radiotherapy, and surgery compared with surgery alone for esophageal cancer: CALGB 9781. J Clin Oncol 26(7): 10861092, 2008.

8 Walsh TN, Noonan N, Hollywood D, Kelly A, Keeling N and Hennessy TP: A comparison of multimodal therapy and surgery for esophageal adenocarcinoma. N Engl J Med 335(7): 462-467, 1996.

9 Bosset JF, Gignoux M, Triboulet JP, Tiret E, Mantion G, Elias D, Lozach P, Ollier JC, Pavy JJ, Mercier M and Sahmoud T: Chemoradiotherapy followed by surgery compared with surgery alone in squamous-cell cancer of the esophagus. N Engl J Med 337(3): 161-167, 1997.

10 Burmeister BH, Smithers BM, Gebski V, Fitzgerald L, Simes RJ, Devitt P, Ackland S, Gotley DC, Joseph D, Millar J, North J, Walpole ET and Denham JW: Trans-Tasman Radiation Oncology Group; Australasian Gastro-Intestinal Trials Group. Surgery alone versus chemoradiotherapy followed by surgery for resectable cancer of the oesophagus: a randomised controlled phase III trial. Lancet Onco l6(9): 659-668, 2005.

11 Cunningham D, Allum WH, Stenning SP, Thompson JN, Van de Velde CJ, Nicolson M, Scarffe JH, Lofts FJ, Falk SJ, Iveson TJ, Smith DB, Langley RE, Verma M, Weeden S and Chua YJ: MAGIC Trial. Participants. Perioperative chemotherapy versus surgery alone for resectable gastroesophageal cancer. N Engl J Med 355(1): 11-20, 2006.

12 Ychou M, Boige V, Pignon JP, Conroy T, Bouché O, Lebreton G, Ducourtieux M, Bedenne L, Fabre JM, Saint-Aubert B, Genève $\mathrm{J}$, Lasser $\mathrm{P}$ and Rougier $\mathrm{P}$ : Perioperative chemotherapy compared with surgery alone for resectable gastroesophageal adenocarcinoma: an FNCLCC and FFCD multicenter phase III trial. J Clin Oncol 29(13): 1715-1721, 2011.

13 Hagiwara K, Kochi M, Fujii M, Song K, Tamegai H, Watanabe M, Takayama Y, Suda H, Teshima Y and Takayama T: Radiochemotherapy for esophageal squamous cell carcinoma in elderly patients Hepatogastroenterology 61(134): 1617-1622, 2014.

14 Kurokawa Y, Muto M, Minashi K, Boku N and Fukuda H: Gastrointestinal Oncology Study Group of Japan Clinical Oncology Group (JCOG). A phase II trial of combined treatment of endoscopic mucosal resection and chemoradiotherapy for clinical stage I esophageal carcinoma. Japan Clinical Oncology Group Study JCOG0508. Jpn J Clin Oncol 39(10): 686-689, 2009.

15 Kato H, Sato A, Fukuda H, Kagami Y, Udagawa H, Togo A, Ando N, Tanaka O, Shinoda M, Yamana H and Ishikura S: A phase II trial of chemoradiotherapy for stage I esophageal squamous cell carcinoma: Japan Clinical Oncology Group Study(JCOG9708). Jpn J Clin Oncol 39(10): 638-643, 2009.

16 Kochi M, Fujii M, Kanamori N, Mihara Y, Funada T, Tamegai H, Watanabe M, Takayama Y, Suda H and Takayama T: Phase II Study of Neoadjuvant Chemotherapy With S-1 and CDDP in Patients With Lymph Node Metastatic Stage II or III Gastric Cancer. Am J Clin Oncol 40(1): 17-21, 2017.

17 Kochi M, Fujii M, Kanamori N, Kaiga T, Takahashi T, Kobayashi M and Takayama T: Neoadjuvant chemotherapy with S-1 and CDDP in advanced gastric cancer. J Cancer Res Clin Oncol 132(12): 781-785, 2006

18 Sakuramoto S, Sasako M, Yamaguchi T, Kinoshita T, Fujii M, Nashimoto A, Furukawa H, Nakajima T, Ohashi Y, Imamura H, Higashino M, Yamamura Y, Kurita A and Arai K: ACTS-GC Group. Adjuvant chemotherapy for gastric cancer with S-1, an oral fluoropyrimidine. N Engl J Med 357(18): 1810-1820, 2007.

19 Sasako M, Sakuramoto S, Katai H, Kinoshita T, Furukawa H, Yamaguchi T, Nashimoto A, Fujii M, Nakajima T and Ohashi Y: Five-year outcomes of a randomized phase III trial comparing adjuvant chemotherapy with S-1 versus surgery alone in stage II or III gastric cancer. J Clin Oncol 29(33): 4387-4393, 2011.

20 Noh SH, Park SR, Yang HK, Chung HC, Chung IJ, Kim SW, Kim HH, Choi JH, Kim HK, Yu W, Lee JI, Shin DB, Ji J, Chen JS, Lim Y, Ha S and Bang YJ: CLASSIC trial investigators. Adjuvant capecitabine plus oxaliplatin for gastric cancer after D2 gastrectomy (CLASSIC) 5-year follow-up of an open-label, randomised phase 3 trial. Lancet Oncol 15(12): 1389-1396, 2014.

21 Nakajima T and Fujii M: What make differences in the outcome of adjuvant treatments for resected gastric cancer? World J Gastroenterol 20(33): 11567-11573, 2014.

Received April 14, 2017

Revised May 1, 2017

Accepted May 8, 2017 